\title{
Chapter 1 \\ Introduction to the Concepts and Use of ERA Acute
}

\begin{abstract}
Introducing the main concepts of ERA Acute, this chapter describes the overall framework and purpose of the methodology. ERA Acute is a recently developed oil spill risk assessment (OSRA) methodology for quantification of oil spill impacts and risk (Environmental Risk Assessment, ERA). It covers four environmental compartments; sea surface (seabirds, turtles, marine mammals), water column (fish eggs/larvae), shoreline and seafloor (species and habitats) using continuous impact functions and introduces the Resource Damage Factor (RDF). The methodology depends on external oil spill modelling and input data related to the presence and vulnerability of Valued Ecosystem Components (VECs). ERA Acute is developed to provide an improvement over the currently used "MIRA" method on the Norwegian Continental Shelf (NCS) and is better suited for risk management, decision-making and analyses from screening studies to full environmental risk assessments.
\end{abstract}

Keywords ERA Acute concept $\cdot$ ERA Acute input data $\cdot$ Environmental compartments $\cdot$ Environmental risk assessment $\cdot$ Environmental risk management

\subsection{Why the Need for a New Methodology?}

Environmental Risk Assessments (ERAs) are a crucial part of planning and execution of offshore oil and gas $(\mathrm{O} \& \mathrm{G})$ activities and are important in supporting the $\mathrm{O} \& \mathrm{G}$ industry in environmental risk management (ERM) of their operations worldwide. In varying regulatory frameworks, operators must ensure overall high environmental performance, whether it is in applications for permits, or in planning or operation of activities where there is a risk of an accidental oil spill. Quantitative ERAs of acute oil spills at different levels of detail are used to support decision-makers in complying with regulations, e.g. for activity applications and planning processes for oil spill response.

Several ERA models, assessing potential impact and risk from an acute oil spill, exist and are available for global use. A recent overview of some applicable models 
for risk assessments in the Arctic is given in Wenning et al. (2018). Some available models for use in a risk assessment process are oil spill trajectory models. The Bureau of Ocean Energy Management in the US uses "Oil Spill Risk Analysis Model" (OSRAM) which calculates probabilities of surface oiling at specific locations (Guillen et al. 2004, BOEM webpage for OSRAM). The "Blowout and Spill Occurrence Model" (BLOSOM) was developed by the U.S. Department of Energy's National Energy Technology Laboratory, and has e.g. been used to evaluate the coastal communities' vulnerability to oil spills in the Gulf of Mexico area from deepwater and ultra-deepwater blowouts (Nelson et al. 2015; NETL Factsheet 2019). Readily available also is the GNOME-model (General NOAA Operational Modeling Environment) by the US National Oceanographic and Atmospheric Administration. The OSCAR (Oil Spill Contingency and Response) model by SINTEF is frequently used on the Norwegian Continental Shelf (NCS). Also available is the MIKE model by DHI for surface and water column modelling. These oil spill trajectory models make use of Geographical Information Systems (GIS) to geographically locate areas of potential concern but may vary with respect to the number of environmental compartments they include. Several include response option modelling, e.g. GNOME and OSCAR. Taking it a step further, some established models include an impact assessment of potentially harmed Valued Ecosystem Components (VECs). The SIMAP model by RPS ASA has oil spill trajectory modelling integrated and is a coupled oil spill modelling and risk assessment by also including exposure and impact modelling to wildlife groups. Links to the home pages of the mentioned models are given in the reference section to this chapter.

On the NCS the quantitative "MIRA" method has been used as an industry standard since the 1990s (NOROG 2007), for execution of ERAs for Authority applications, planning and other pre-spill analyses. MIRA uses input of external oil spill fate and transport modelling, for example by using input from the OSCAR model, or similar trajectory models to calculate potential population losses of wildlife and impacted shoreline habitats. The industry and regulators in Norway have seeked an improvement over MIRA, and a model that could be globally applicable in line with "Guideline for oil spill risk assessment and response planning for offshore installations" (IPIECA-IOGP 2013). ERA Acute was developed to meet these requirements. Like MIRA, ERA Acute does not contain an integrated oil spill trajectory model but allows the user to select a preferred oil spill model giving the required input format. The methodology is expected to replace MIRA on the NCS following comprehensive testing, validation and a series of case studies comparing the two methods. The case studies are not described in this book. Like MIRA, ERA Acute uses the results of oil spill trajectory statistics, primarily aimed at assessments for pre-activity planning. 


\subsection{Methodology, Model and Software}

The ERA Acute methodology provides updated impact and restoration functions based on available international research, both peer-reviewed papers and scientific reports. It is designed to have robust and continuous damage functions in four compartments, i.e. a harmonized framework of calculations, whilst maintaining scientific integrity of each compartment. ERA Acute does not include an oil spill trajectory model but utilizes input from any oil spill model that can provide results from a multitude of single simulations exported to a standardized grid format. VECs are natural resources, e.g. seabirds, shoreline habitats etc. for which impacts are calculated. The VEC input data are gridded to the same standardized format and each VEC is ascribed to the compartment where the main impact occurs.

The methodology of ERA Acute is an analytical concept which depends on input data from preceding models, which need to provide data of adequate quality. The ERA Acute model itself contains mathematical functions in a sequence that make up the impact and restoration calculations, and the methodology also has defined concepts related to the recommended presentation of the analytical endpoints of these calculations. A software tool has been developed to run the model calculations, with an interface to assist users in setting up the correct inputs, run the calculations and view the results. However, the software is not the focus of this book and the methodology can be used independently. The methodology, including the descriptions of use of input data are described in an industry guideline (NOROG 2020), whereas the biomathematical model functions and sequence of calculations are described as an overview in this book and in the underlying development reports (see list of references). As far as possible in this short book, we have included the equations.

Figure 1.1 shows an overview of the ERA Acute methodology and the division into: Inputs (top two boxes), model calculation units (middle box) and result presentation concepts (bottom box). The required input data on VECs and oil drift simulations are not included in the model nor included in the software tool (lilac background), offering a flexibility in choice of oil spill model and VEC data to be used in the risk assessment. Each of the impact and restoration calculations contain parameter values that are provided by the user as input files (see Sect. 1.4.3). For the parameter values, default values are available suitable for global use. These may be changed if specific knowledge exists about local resources (VECs) etc., thereby reducing uncertainty. The functions (middle light orange box) calculate impacts and restoration-related results and summarize and create statistical results. The functions and their sequences have been implemented in the software tool calculator. The software tool also includes interfaces for setup, calculation and presentation of recommended results (lower light orange box). 


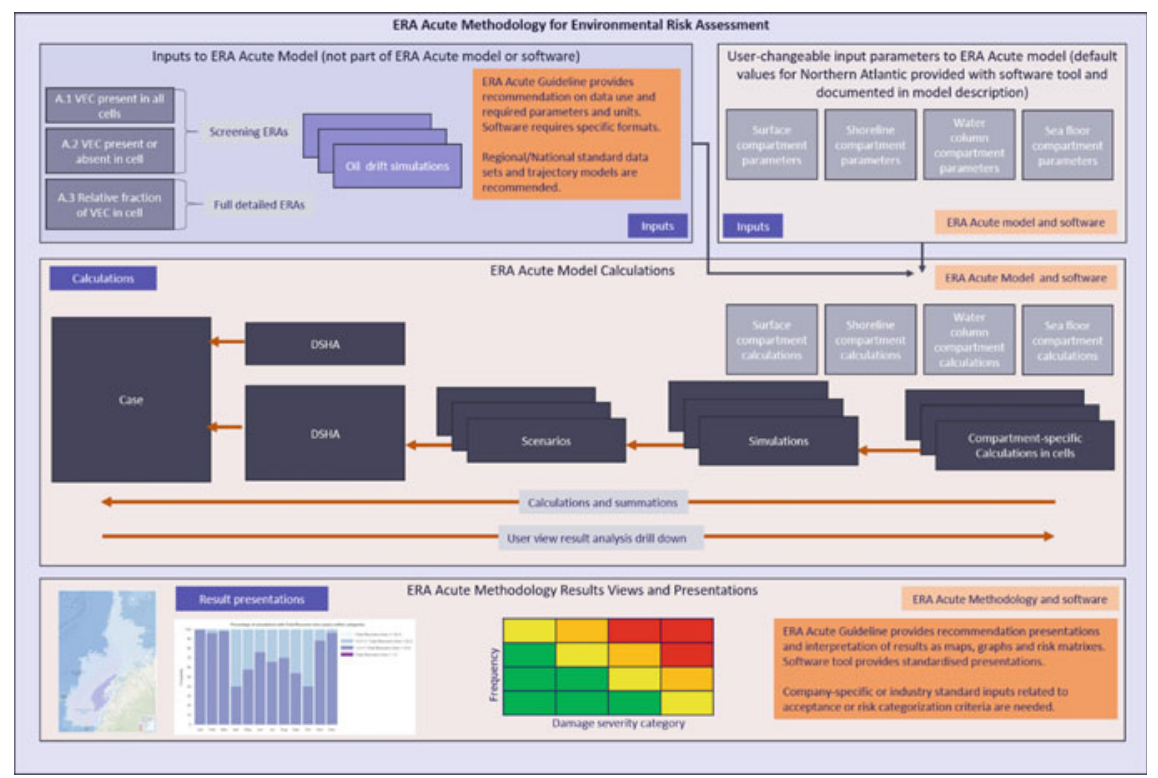

Fig. 1.1 The ERA Acute methodology showing the division into Inputs (top two boxes), model calculation units (middle box) and result presentation concepts (bottom box). Data on resources (VECs) and oil drift simulations are not included in the model (lilac background) whereas the ERA Acute conceptual model documentation includes recommended values for input parameters for each compartment (upper right light orange box), and the calculations (middle light orange box). The software includes setup, calculation and presentation (lower light orange box) tools. (DSHA — defined situation of hazard and accident)

\subsection{Basic Concepts of ERA Acute}

\subsubsection{Four Compartments}

ERA Acute uses gridded data on the biological distribution of a VEC (i.e. biological resources: species, communities or habitats) within the area of interest, in four environmental compartments mentioned above: Sea surface, shoreline, water column and seafloor. The VECs are assigned to the compartment where their impact occurs. Some VECs may occupy more than one compartment, for example representing resources in different life stages that have separate data sets. Whilst it was important to design a common framework for the ERA Acute methodology calculations, the different nature of the impact mechanisms is reflected in the risk functions of each of the four compartments. Emphasis has also been placed on keeping data transparency throughout the calculations. 


\subsubsection{ERA Acute Uses Continuous Risk Functions}

Where category-based models like MIRA (NOROG 2007) assume a probability distribution of impacts in categories based on oil amount intervals, ERA Acute applies a continuous impact function based on the exposure, lethality given exposure and the VEC fraction present in the cell. The continuous impact and damage functions are believed to be more suitable for e.g. Net environmental benefit analysis (NEBA)/Spill Impact Mitigation Assessments (SIMAs) than category-based assessments, since more subtle differences in exposure will give different impact results which the risk assessor can then evaluate for decision making.

\subsubsection{Two Main Steps-Three Levels of Detail}

Questions to be answered by ERA-related studies vary in demand for detail, depending on e.g. the phase of the project, the maturity of petroleum activity in the region, or the sensitivity of the environment. The model framework is therefore designed to be flexible in its uses, and ERA Acute calculates several endpoints. Chapter 2 is dedicated to the application of ERA Acute results for environmental risk management purposes.

The modelling is carried out in two main steps. In the first step (A), ERA Acute methodology uses input from the oil spill trajectory model and the VEC data to calculate impact in each grid cell for each oil drift simulation (see Fig. 1.6). The results are summed up or averaged for each VEC in all compartments. In the second step (B), recovery results are calculated.

\subsubsection{Impact Calculation (Step A)}

Impact modelling in ERA Acute uses the framework of probability of exposure $\left(p_{\text {exp }}\right)$, probability of lethal effect given exposure $\left(p_{l e t}\right)$ and presence of vulnerable resources (VEC "unit") to calculate the mortality in each grid cell for each spill simulation. This basic principle is the same in all compartments, however the actual calculation of exposure and lethal effect, as well as the VEC "unit" in each compartment reflects the differences in mechanism of harmful action. The exposure and lethality parameters are determined from the compartment-specific oil spill impact parameters, such as oil coverage above a certain film thickness on the sea surface to induce a mortality to seabirds, turtles and marine mammals and oil mass on the shoreline to induce impact to sensitive shoreline types. ERA Acute uses continuous exposure-response relationships in order to predict mortality, meaning that a change in exposure from the oil drift will lead to a change in mortality as output. For species at the sea surface or in the water column compartment, the total injury is calculated for each spill simulation by summarizing the impact in all grid cells affected by the simulation. 
This will give a total population loss of seabirds/mammals or fish larvae loss for each simulation. For the shoreline compartment, the impact is also summarized to a total shoreline impact in kilometers, distributed on the various shoreline rankings of Environmental Sensitivity Indexes (ESI) (NOAA 2002). Similarly, for the seafloor compartment, the total impact is given in $\mathrm{km}^{2}$ impacted for each benthic habitat or community.

ERA Acute can use three levels of detail in the continuous-function impact calculations, depending on availability of data on VEC occurrence and distribution. Two screening levels allow for ERA Acute risk assessment even if VEC data are limited or even missing. Oil spill trajectory input data are needed at all levels, however, not all analyses may require complex modelled input of both oil and VEC. Simplified oil spill input data can be prepared manually for screening purposes or based on actual knowledge from a spill.

Impact calculation level A.1 is used if there are no data on the presence of environmental resources available (no VEC data). It uses only the oil drift simulations to determine exposure and potential mortality and assumes the most sensitive resource is present in all cells as a conservative estimate of the potential risk area. This quantitative result is suitable for identifying areas at risk in a screening or early phase project decision, or for identifying which area to focus on filling data gaps. It is particularly useful in areas where no knowledge exists on the presence of VECs, allowing ERA Acute to be used for screening purposes (see Sect. 2.3) or decision support where a specific detail on particular species is not needed (see Sect. 3.2.1). Parameters that relate to the sensitivity of the species are provided as default values based on globally applicable data, e g. global VEC wildlife groups.

Impact calculation levels A.2 and A.3 use resource data to identify specifically where impacts and risks to resources are highest. Level A.2, the second screening level, includes knowledge and data of whether the most sensitive VEC is present or not in the cell, thereby excluding cells with known non-presence of sensitive VEC (see Sect. 1.4.2.2). At the most detailed level (A.3), the full-resolution data on VEC abundance distributions are used (i.e. population fraction in each grid cell), providing a more accurate measure of potentially impacted fractions of the VEC (population loss, impacted coastline length or seafloor area). This is suitable for more detailed studies, e.g. analyses in sensitive areas, detailed decision making etc. and are used for further calculations in the next step, recovery time calculations (step B).

\subsubsection{Recovery Estimation (Step B)}

In the second main step (B), the duration of the impact (i.e. the total recovery time) is calculated as three time-factors for each VEC; the impact time $\left(t_{\text {imp }}\right)$ describes the time until full impact is seen, lag time $\left(t_{l a g}\right)$ is the time before restoration can commence (where relevant), and restoration time $\left(t_{\text {res }}\right)$ is the time it takes for the resource to recover from re-growth starts to pre-spill levels. For the four environmental compartments, different parameters and sub-models are used to calculate restoration times. The restoration time for birds and marine mammals is calculated 
based on the population loss using a discrete logistic growth model. For the water column, a global fish-population model has been built that translates the egg or larvae loss to a restoration time for the adult spawning stock biomass. The shoreline restoration calculations use a simpler look-up table to estimate the restoration time for a specific ESI shoreline type. Restoration time in soft seafloor substrates is calculated by a linear relationship between the amount of oil in the sediment above a threshold value and the expected maximum concentration of Total Hydrocarbon (THC) resulting from sedimentation of oil.

\subsubsection{Introducing the Resource Damage Factor}

ERA Acute introduces the Resource Damage Factor (RDF) as an index that combines the extent of impact and duration of impact described by the recovery time. RDF was previously denoted Resource Impact Factor (RIF) (Stephansen et al. 2017a, b; Spikkerud et al. 2006) but this was updated to better clarify that the concept includes both extent and duration of the impact in the damage assessment. In Fig. 1.2, $\mathrm{RDF}$ is illustrated by the geometric area representing the combination of extent ( $\mathrm{y}-$ axis as loss) and duration (x-axis). Its calculation is slightly different in the four compartments (Chap. 3). The RDF supplements the recovery time as an endpoint of the damage assessment. Figure 1.2 illustrates impact as a fraction of the VEC lost (e.g. population loss) and the calculation of time factors and RDF.

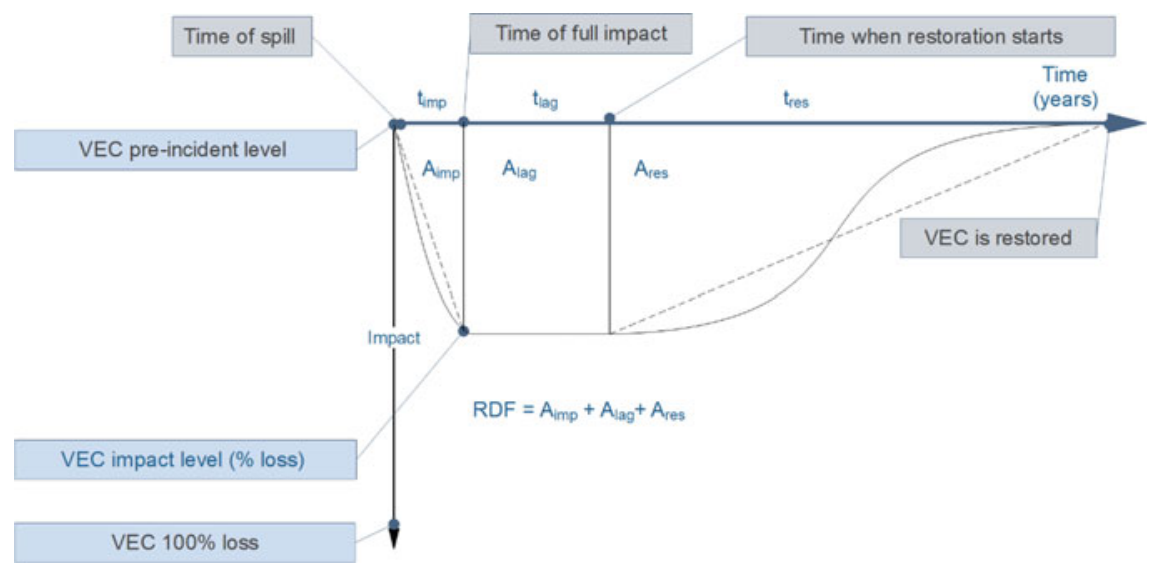

Fig. 1.2 Basic illustration of the use of impact as resource (VEC) loss and time factors to calculate the Resource Damage Factor as the geometric area representing the combination of extent and duration of impact 


\subsection{Inputs Needed for ERA Acute}

\subsubsection{Oil Spill Trajectory Modelling}

ERA Acute does not include an oil spill trajectory model. Oil drift simulation models used should provide results from a multitude of single simulations exported to a standardized grid format. Each simulation has a start date and a duration, which is used to identify the relevant month. Each cell in each simulation has output values of the necessary oil inputs.

Although the ERA Acute project has used SINTEFs oil spill trajectory model Oil Spill Contingency And Response (OSCAR) as an example for development purposes, oil drift simulations are carried out separately using any preferred oil drift model that can provide the necessary parameters in the right format for input to ERA Acute. The format (the parameters and their units) is specified a separate report (Brönner et al. 2017).

A Defined Situation of Hazard and Accident (DSHA) may consist of one or several scenarios (see Sect. 3.1) where each scenario represents a rate-duration combination and a spill location depth and is modelled in numerous simulations. The scenarios have different probabilities, defined by a probability distribution. Single simulation results must contain the oil exposure-related input parameters for each compartment in each cell. Initial impacts are calculated in individual cells of single simulations for every VEC. The impact mechanisms are different in each compartment. Results from the cells and simulations are aggregated to scenario statistics and DSHA assessments using the probability distributions of the individual rates, durations and spill depth. In this way, results are averaged and/or summarized in a series of steps that allow the investigation of results at several levels. Impacts can be viewed in individual cells and for single simulations or can be summarized for scenarios or whole DSHAs. A case can consist of one or more DSHAs.

In order to include the large variation in drift and fate of the oil following an accidental oil spill, the oil spill modelling is carried out using a stochastic approach with numerous simulation runs using different historical start dates, representing a variety of wind and current situations throughout the simulated spill and modelling duration from a hindcast archive of historical wind and current. The output is a significantly large number of spill simulations, each representing a historical situation of how the oil spill would have behaved and impacted different areas on the sea surface, water column, seafloor or shoreline had it started on a specific historic date. In this way seasonal and annual variations are included in the statistical results. For each oil spill simulation, various endpoint parameters are recorded for each grid cell that will be used to quantify the impact (mortality or habitat loss) for various VECs. This includes parameters like:

- oil mass and oil film thickness on the sea surface

- surface oil coverage in grid cell above a threshold film thickness

- accumulated oil mass in shoreline or seafloor grid cells 
- total water column concentrations of oil (droplets and dissolved oil components) or a potential accumulated fish larvae mortality calculated over the duration of the simulation based on the composition of the hydrocarbons at each time step and their toxicity, if available from an external model.

Many of the input parameters to ERA Acute from oil drift modelling are averaged over the spill simulation time steps, i.e. oil film thickness is the average oil film thickness in a grid cell when there has been oil in the grid cell during the simulation. For the shoreline and seafloor compartments, the accumulated oil mass at the end of the simulation is recorded and given as output of the oil drift model, in turn used as input to ERA Acute to quantify the impact in these compartments.

\subsubsection{Valued Ecosystem Components}

As mentioned, a VEC in ERA Acute is a natural resource for which the environmental risk is assessed. VEC data are used for the more detailed levels of analysis in ERA Acute (see description of the levels in Sect. 1.3.3) and VECs are assigned to an environmental compartment of their primary exposure. The VEC can be a population of seabirds, turtles or marine mammals, sensitive early life stages (ELS) of a fish population, a shoreline type or seafloor species or habitat/community "represented" by a key species.

\subsubsection{Analysis Level A.1 Impact Analysis}

At level A.1 impact analysis, VEC data are not needed (see Sect. 1.3.3.1).

\subsubsection{Analysis Level A.2 Impact Analysis}

If VEC data are limited to a geographic area comprising the location and extent of a habitat of a species, a spawning area or similar, but no details are known about the density distributions within that area, simplified VEC data can be prepared for a compartment to allow for an ERA Acute analysis at level A.2. The data are simple gridded polygon data where the VEC may be present (see Sect. 3.2.1), which will be matched with the oil spill input to limit the impact assessment to specific areas. Many globally available GIS data are readily available for this level, requiring only gridding of the polygons. 


\subsubsection{Analysis Level A.3 Impact Analysis}

VEC input data at the highest level are gridded to the same standardized format as oil spill trajectory simulations, containing VEC population (or equivalent) fractions in each cell. Each VEC is ascribed to the compartment where the main impact occurs. The parameter values used for the VECs can be changed where relevant, e.g. for different regions, but globally applicable default values are available.

In order to calculate the most detailed potential impact and recovery of a VEC, its distribution needs to be mapped into the same grid cells as the oil drift output. For a population, each grid cell will have a value representing the fraction of the population present in that cell. Environmental risk will vary between seasons with the VEC distribution, the VEC distribution data therefore have a monthly resolution. For shorelines, the shoreline length of each ESI ranking (NOAA 2002) in each grid cell is used as the VEC unit. For seafloor habitats and/or communities, the area distribution in $\mathrm{km}^{2}$ within each seafloor grid cell is used.

The VEC data are entered for each of the four environmental compartments in ERA Acute (Fig. 1.3):

- Sea surface compartment-(Sea birds, marine mammals, turtles)

- Water column compartment-(Fish stocks represented by eggs and larvae)

- Shoreline-(ESI shoreline ranking of shoreline)

- Seafloor-(Benthic habitats/communities or key species).

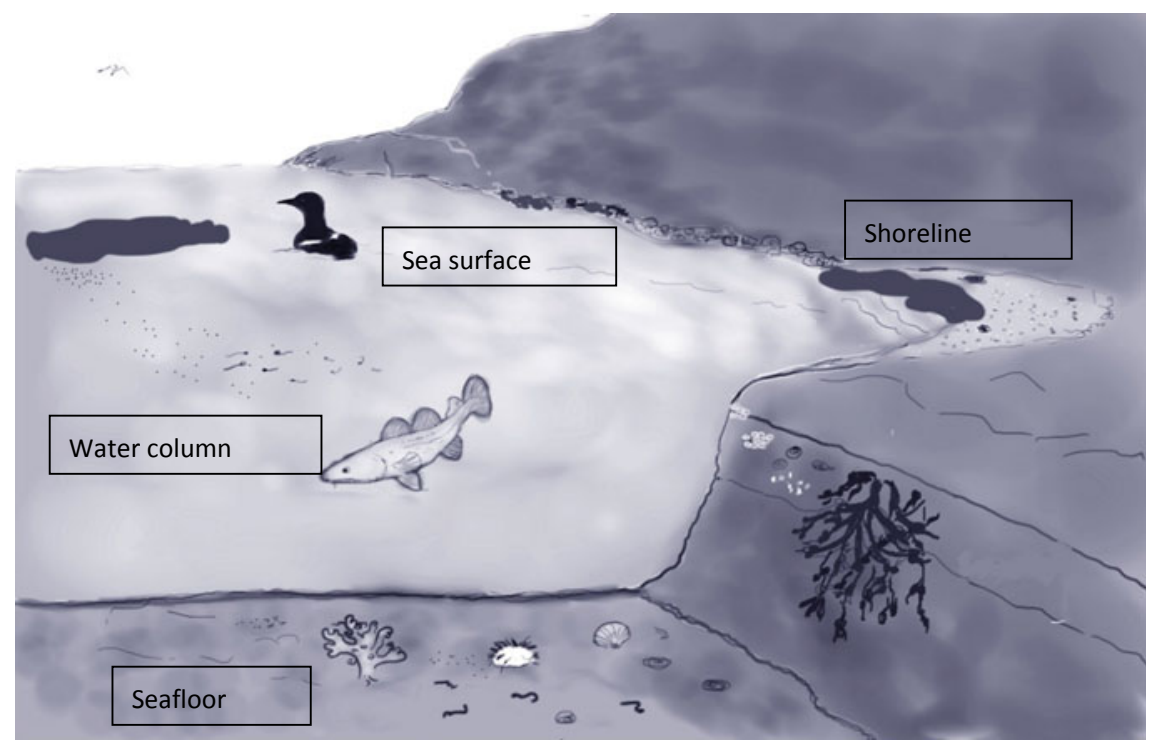

Fig. 1.3 Valued ecosystem components are natural resources that are assigned to one of four compartments sea surface, water column, shoreline or seafloor (Illustration C. Stephansen) 
As for oil drift simulations, VEC-data are entered as input data to ERA Acute. Figure 1.4 shows a map of a monthly distribution of a sea bird VEC with partial data coverage.

The distribution of a VEC population within an area is sensitive to the quality of data, which directly affects the accuracy of the impact calculations. VEC data at the A.3 level should be prepared using caution and scientific approaches to handle uncertainty (see Chap. 4). Sources of quality data from specialist scientific institutions that carry out VEC distribution modelling, validated with observations are preferable. For example, for seabirds, colony data with additional foraging area distributions around the colonies are relevant for breeding seasons, whereas data for

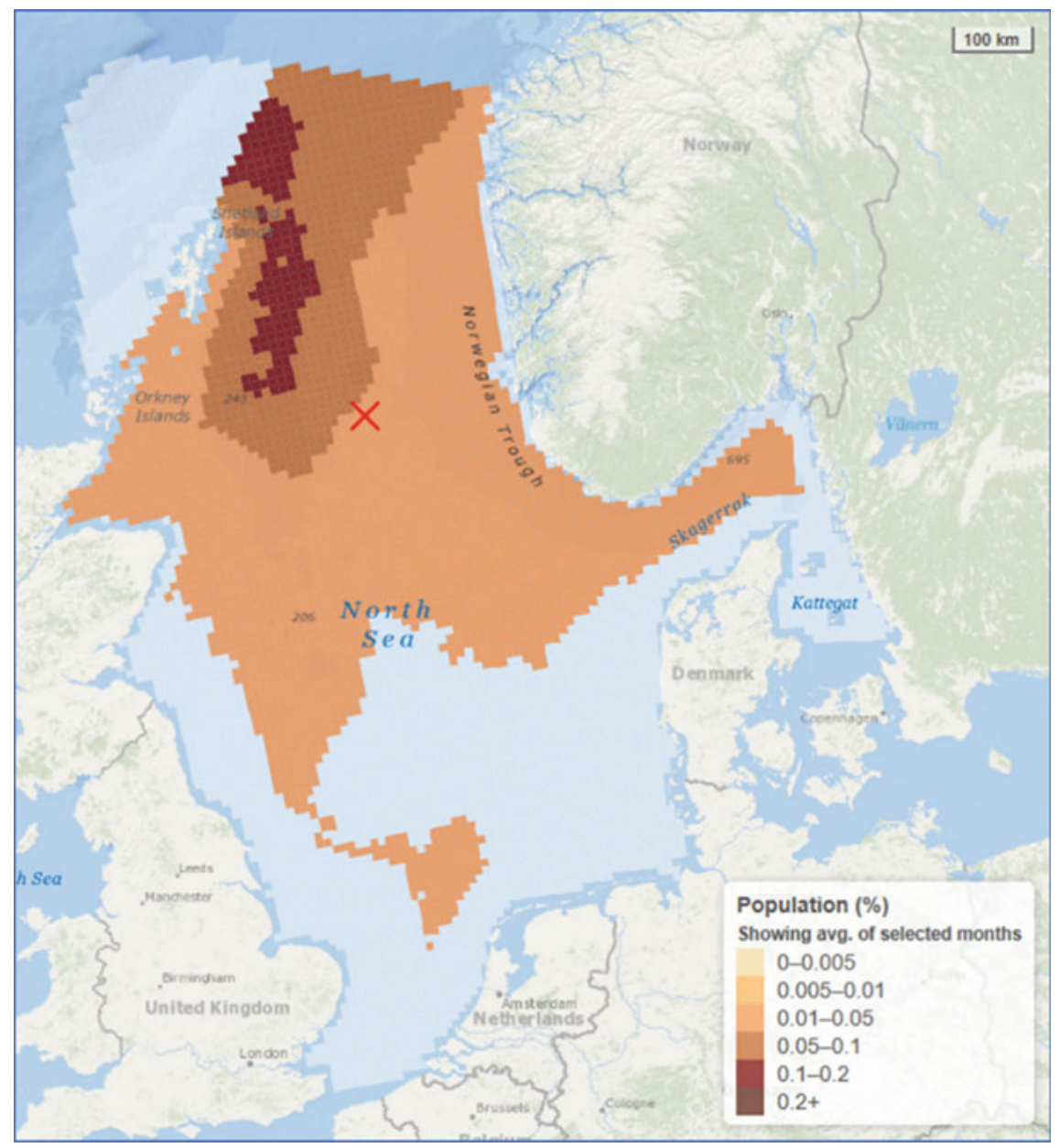

Fig. 1.4 Example of a monthly distribution map showing population fractions of a seabird VEC in each grid cell with a limited geographic coverage of the data set 
migration and wintering areas could be established using loggers and other tracking devices, machine learning techniques etc. to estimate and validate distributions. For NCS, the authors have prepared industry standard seabird data using species distributions from the specialist scientific institutions Norwegian Polar Institute (NPI) and Norwegian Institute of Nature Research (NINA) under the SEAPOP and SEATRACK programs (http://www.seapop.no/en/). Data prepared by agent-based modelling under MARAMBS (Marine Animal Ranging Assessment Model Barents Sea, DHI) (http://marambs.dhigroup.com/) have also been utilized. Construction of VEC data for the international validation cases are described in Sect. 4.1.4. For all ERA Acute parameters, default values are suggested based on assessment of available scientific knowledge. However, parameter values related to the VEC and specific population in question should be assessed, tested and if necessary, adjusted and validated for the specific VEC population.

\subsubsection{Model Input Parameters}

ERA Acute calculation functions use many parameters which have values that are specific for certain species or regions (upper right light orange box in Fig. 1.1). Recommended values based on literature studies are supplied for use in the Northern Atlantic/NCS region with the software tool and documented in the methodology development reports (Bjørgesæter and Damsgaard Jensen 2015; Brude et al. 2015; Brönner et al. 2015; Stephansen et al. 2015). These values can be changed by the user if other values are considered more appropriate for another specific region or when future research provides new knowledge. However, it is strongly recommended to obtain consensus for the parameter values used in analyses that are carried out for example within the same regulatory framework or region, in order to compare analyses.

\subsection{From Spill Scenario to Case and from Damage to Risk}

The basic concepts of impact and recovery calculation in ERA Acute have been described in Sect. 1.3 and are described in greater detail in Chap. 3. In order to calculate risk from the estimated consequences, the probability of the damage also has to be taken into account. For this, the case needs to be analyzed with the correct distribution of probabilities between the elements that contribute to the risk.

To give an example, say a risk assessor needs to analyze the annual environmental risk related to accidental oil spills for an oil field in production. This is the Case. The possible spills that contribute to the analysis case may be different DSHAs (see Sect. 1.4.1) A DSHA may be pipeline leakages or blowouts from loss of well control during drilling or maintenance, or other spill scenarios related to the activity or annual activities on the field. The first step is to define which DSHAs that make up the case 


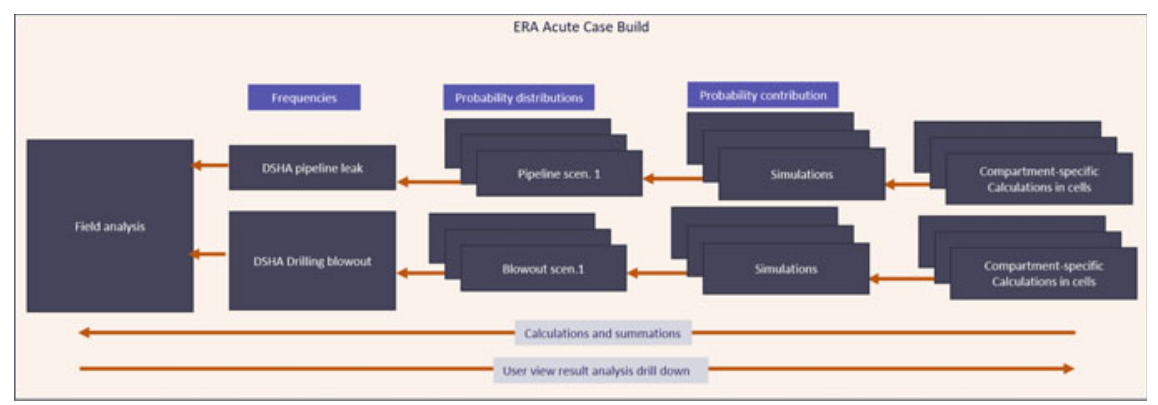

Fig. 1.5 A case can consist of several DSHAs that in turn consist of one or several scenarios. For each scenario several simulations are run (with equal probability contribution within the scenario), giving results in cells

to be analyzed, and to determine the frequency for each. Each of these DSHAs have individual frequencies (probabilities of occurring) per annum or per activity, based on statistics from historic incidents.

A DSHA in turn consists of one or several spill scenarios, which in ERA Acute is defined as a spill situation characterized by all the properties of the scenario where the rate and duration differ between the scenarios. One scenario within a DSHA is defined by a spill rate and duration combination, all other properties (location, oil type etc.) are the same within the DSHA. A blowout DSHA, for example, may consist of many spill scenarios representing surface or seabed releases or a range of blowout rates and durations representing spills from open hole, annulus or drill pipe. The spill scenarios are commonly presented in a rate-duration matrix with a probability distribution between the scenarios, given as input to the calculations.

For each scenario, several oil drift simulations are run as described above. The calculations are run "bottom-up" starting with the single cell calculations in the simulation and ending with the results for the whole case.

The results are typically viewed from the case perspective and drilled down to scenarios for example to illustrate which of the spill scenarios contributes the most to environmental risk (Fig. 1.5). As oil and gas activities can have many different spill scenarios, it is also relevant to show the individual risk for each spill scenario or the aggregated risk of the DSHA or the Case. From a scenario, results can be drilled down even to single simulations, relevant e.g. for viewing extreme situations. Figure 1.6 shows this model framework up to a DSHA.

\subsection{What Can ERA Acute Results Be Used for?}

ERA Acute has many endpoints (impact, recovery times and RDF), and the flexibility in the use of data detailing makes ERA Acute useful for both screenings and more in-depth risk assessments in several Environmental Risk Management applications (see Chap. 2). 


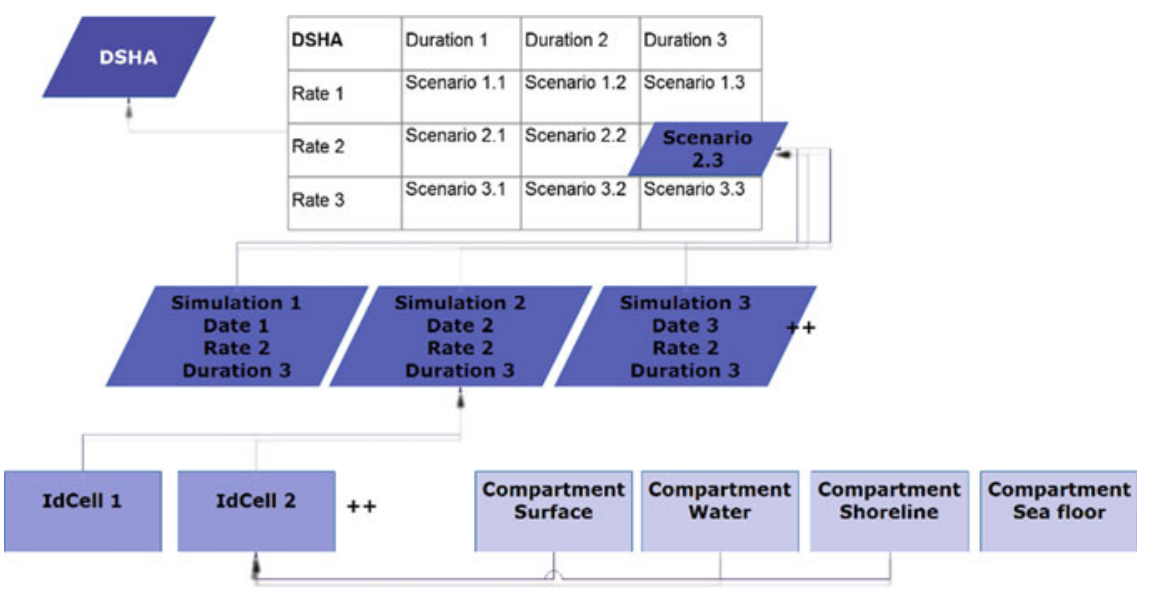

Fig. 1.6 Structure of ERA Acute with four compartments and cell and simulation-to-DSHA build. Each of the spill scenarios has a probability

Results are presented as average impacts or time factors, maximums and minimums, as graphs of monthly results for one or several VECs, probability distributions and frequencies. A common set of recommended presentation formats are developed to facilitate standardized analyses and user-friendly risk analysis endpoints. In-depth knowledge of the sensitivities of the model and its inputs is a necessary background for setting operator-specific boundaries of risk acceptance for each endpoint, as well as adapting datasets and input parameters in the model.

As mentioned, at its most detailed level, ERA Acute requires several types of input data as well as understanding of the implications of the analysis area scale and the transparency of input data. Screenings from the first levels provide a good basis for decision-support in early stages of project development, whereas the most detailed results are beneficial in other environmental risk management processes, authority applications etc. Endpoints from a variety of calculation steps can be presented or post-processed to answer questions in analyses such as ERAs or impact assessments or can be used to compare and select the response option(s) that will best mitigate the overall impact and risks such as for Spill Impact Mitigation Assessments, Net Environmental Benefit Analysis and company-specific risk matrix approaches (see Chap. 2). It can therefore provide quantitative input to comprehensive comparative methods such as described by Bock et al. (2018), which may also include stakeholder engagement processes and value-based weighting/scoring.

The use of a continuous function in the impact calculations is expected to be valuable when comparing e.g. risk mitigation by use of oil spill recovery options, since the impact calculations will be able to better detect the effect of small variations in exposure than a model based on oil amounts in categories. Category-based models will assume the same impact probability distribution whether the oil amount is the lowest or the highest amount within the category interval. For example, in MIRA the impact is the same whether the oil amount in a cell is 1 ton or 99 tons, whereas 100 tons 
of oil brings the impact into the next impact category. Using the continuous function in ERA Acute will mitigate this shortcoming and is especially useful for comparing risk between alternative cases and solutions, such as for SIMAs. Although in some cases a category-based method may result in higher impact for a small spill, a continuous function will be more sensitive to subtle changes in exposure. ERA Acute is therefore expected to be more suitable for analyzing efficiency of mitigation of smaller spills than a category-based method, which is especially important in environmentally sensitive areas.

Because ERA Acute quantitatively evaluates the impact and risk in grid cells, risk assessors can view results in maps at various assessment steps using a geographical information system for any region globally. An ERA Acute environmental risk map for a VEC can show where the risk is high or low, for example by showing average population loss from all simulations or by highlighting the worst case by showing maximum population loss. The environmental risk assessor can identify areas of high risk for use in decision support and spill response planning, independently of the region. All georeferenced results are useful for strategic use of geographic information in risk management and planning.

For detailed studies of scenario impacts, analysis endpoints can be plotted against frequencies in risk matrixes. Since many spill simulations have been carried out for each spill scenario, a probability distribution is obtained of different outcomes in terms of environmental damage. The various impact and recovery time endpoints in ERA Acute can be categorized according to level of seriousness and the probability for defined categories of environmental damage can be calculated, e.g. "minor", "moderate", "serious" etc. These severity categories are subjective, based on operator preferences or industry standards where relevant (see Chap. 2 for more detail). The applications of the methodology are discussed in Chap. 2.

\subsection{Model Sensitivity and Uncertainty Issues}

As a quantitative impact and restoration model, The ERA Acute methodology attempts to describe in mathematical terms the magnitude and duration of the impact from an accidental oil spill. The ability of such a model to accurately quantify the relationship between the exposure and the impact in terms of mortality depends on our understanding of underlying mechanisms of harmful action and how well these can be implemented into mathematical functions. In developing such models, there are numerous decisions to be made, regarding e.g. complexity versus data availability, simplification versus inaccuracy etc. It has been a major goal of the project to develop a model that could be used robustly if there is a low availability of data on presence of resources, but also to be able to utilize high-quality data where these are available.

As a model that uses data on resource presence and exposure-parameters from oil drift simulations to determine exposure and lethality probabilities (denoted $p_{\text {exp }}$ and $p_{\text {let }}$, described in Chap. 3), the model is naturally sensitive to these and other inputs. 
Transparency is therefore needed when presenting results, and as with all other models, users need to verify both data coverage and applicability before entering data into the model. It is recommended that VEC data from the different levels (A.1, A.2 and A.3) are not mixed in the same analysis, e.g. by using presence/no presence data for one VEC and fraction of populations for another VEC, as the calculated results reflect the VEC cell value directly. Different data types should be separated when showing results. Many options are possible for the VEC "unit", the parameter that defines the seasonal and geographical distribution (denoted $N$ in calculations), and the ERA Acute industry guideline (NOROG 2020) will advise on data use for standardized applications of the ERA Acute methodology, including setting the analysis scale. The model implementation software handles differences in data set levels but uses the VEC distribution parameter-value transparently and directly. Users must therefore still apply scientific caution when using data sets from different sources, especially when comparing and interpreting results, as is the case for all models.

Comparing results between compartments can be particularly challenging in models like ERA Acute, because the impact calculations are based on compartmentspecific modes of action and ERA Acute therefore uses compartment-specific functions behind the calculations of lethality and exposure. In e.g. the surface compartment, laboratory-controlled experiments cannot be used to determine the quantitative relationship between dose and response. For some mechanisms, such as smothering or oiling on feathers, a dose-response relationship may not even be clear, although we intuitively understand that a large spill may have a higher impact than a smaller spill. Different approaches have therefore been used in the model development, utilizing as far as possible the knowledge available of impact mechanisms, impact magnitudes after known oil spills and various theoretical approaches. Since the units of the VEC distribution parameter-values and therefore also the endpoints are different, the numerical results in compartments cannot be compared directly, but users may compare for example results as relative to a maximum or in severity categories carefully defined for each compartment. Relative differences in risks within a single compartment may be compared directly between cases. Comparisons are relevant e.g. in SIMA analyses. Keeping the integrity of each compartment is important, both when it comes to the possibility for the analyst to interpret results clearly and for the use of the different endpoints in practical applications. Weighting the result-levels between the four compartments has so far not been part of the methodology development. Also, under different regulatory frameworks there may be different requirements regarding weighting between VECs and/or compartments, or to which degree stakeholders are involved in the assessment process or whether the management process includes stakeholder value scoring of VECs (e.g. Bock et al. 2018).

ERA Acute uses a series of input parameters that are entered into the model at various stages. The ERA Acute methodology has been tested with respect to sensitivity towards important input parameters, using statistical and deterministic testing methods as part of the uncertainty handling (Chap. 4). The model is flexible in design by allowing the user to change some of these parameters if other values are more relevant regionally. However, within a region, it is recommended that the 
parameters are used with consensus within the industry, to obtain comparable results between analyses. As an example; for sediment substrates, finding as accurate as possible values of e.g. total organic carbon content (TOC) will improve the result accuracy. On the other hand, measurements of TOC vary greatly with the local conditions (e.g. background contamination) and the uncertainty may be high. The sensitivity of each model step to its parameters was therefore the subject of a separate study in the project and is the focus of Chap. 4. The input parameters and the proposed standard values were tested for their relative importance to the outcome of the model in the sensitivity and validation phase of the project.

As far as possible, results have also been validated against impact estimates from two historically important oil spills, the Exxon Valdez Oil Spill and the Deepwater Horizon Oil Spill. Comparing the model against historic spills is a particularly interesting and challenging task described in Chap. 4 "Testing and Validating against Historic Spills". Whilst such model validations have many limitations, as impact assessments from the historic spills in themselves also contain uncertainties as results of modelling and calculations, we found that the results of ERA Acute calculations fell within the boundaries of the impact estimates from the spills. We therefore believe that the model is ready to be used and that further experience and work will refine and improve it over time.

\section{References-Introduction}

Bjørgesæter A, Damsgaard Jensen J (2015). ERA Acute phase 3-surface compartment. Acona report to Statoil and Total. Report No. 37571. v.04. Oslo, 22.05.2015. (Supplementary Material, Background Report 3, Surface_compartment_ERA Acute 2015.pdf). https://norskoljeoggass.no/ globalassets/dokumenter/miljo/era-acute/report-3-era-acute-surface_compartment-2015.pdf

Bock M, Robinson H, Wenning R, French-McCay RJ, Walker AH (2018) Comparative risk assessment of oil spill response options for a deepwater oil well blowout: Part II. Relative risk methodology. Mar Pollut Bull 133(2018):984-1000

Brönner U, Nordtug T, Jonsson H, Ugland KI (2015) Joint report —impact and restoration model— water column. SINTEF \& DNV GL Report. SINTEF F26517/DNV GL 1IL8NGC-13. 81 pp. (Supplementary Material, Background Report 5. Water_column_ERA_Acute 2015.pdf). https:// norskoljeoggass.no/globalassets/dokumenter/miljo/era-acute/report-5-era-acute-watercolumn_ compartment-2015.pdf

Brönner U, Stefanakos C, Skancke J (2017) ERA Acute calculator-technical specification. ERA Acute Project Report WP1a, 87 pp. (Supplementary material, ERA Acute Technical Specification 2017.pdf)

Brude OW, Rusten, M, Braathen, M (2015) Development of Shoreline compartment algorithms. DNV GL Report. 1ILBNGC-9. 43 pp (Supplementary Material, Background Report 4 Shoreline_compartment_ERA Acute 2015.pdf). Figure 6. https://norskoljeoggass.no/globalassets/dok umenter/miljo/era-acute/report-4-era-acute-shorelinecompartment-2015.pdf

GNOME model webpage (2020). https://response.restoration.noaa.gov/oil-and-chemical-spills/oilspills/response-tools/gnome.html. Accessed December 2020

Guillen G, Rainey G, Morin M (2004) A simple rapid approach using coupled multivariate statistical methods, GIS and trajectory models to delineate areas of common oil spill risk. J Mar Syst 45(3):221-235 
IPIECA-IOGP (2013) Oil spill risk assessment and response planning for offshore installations. Oil Spill Response Joint Industry Project report

Main Project reports referenced are publicly available in English at. https://norskoljeoggass.no/ miljo/mer-om-miljo/miljorisiko-og-miljorisikoanalyser2/era-akutt/

MARAMBS (as of December 2020). http://marambs.dhigroup.com/

MIKE model webpage (as of December 2020). https://www.mikepoweredbydhi.com/products/ mike-21/sediments/oil-spill

Nelson JR, Grubesic TH, Sim L, Rose K, Graham J (2015) Approach for assessing coastal vulnerability to oil spills for prevention and readiness using GIS and the Blowout and Spill Occurrence Model. Ocean Coast Manag 112:1-11

NETL (2019) Factsheet: Netl's Blowout and Spill Occurrence Model (BLOSOM) https://netl.doe. gov/sites/default/files/rdfactsheet/R-D193_2.pdf

NOAA (2002) Environmental sensitivity index guidelines. Version 3.0. NOAA Technical Memorandum NOS OR\&R 11

NOROG (2007) Method for environmental risk analysis (MIRA, version 2007). Norwegian Oil and Gas Association, Oslo

NOROG (2020) Guidance on environmental risk analyses using ERA Acute. https://www.norsko ljeoggass.no/contentassets/0b122183aeea4e488c057e613e31a81d/guideline-era-acute-120220655164_638235_0.pdf

OSCAR model webpage. https://www.sintef.no/en/software/oscar/

OSRAM model webpage (2020). https://www.boem.gov/environment/environmental-assessment/ oil-spill-risk-analysis-model-osram. Accessed December 2020

SEAPOP and SEATRACK (2020). http://www.seapop.no/en/. Accessed December 2020

SIMAP model webpage (2020) http://asascience.com/software/simap/. Accessed December 2020

Spikkerud CS, Brude OW, Hoell EE (2006) EIF Acute Damage and restoration modelling. DNV Consulting, Report to STATOIL ASA, REPORT NO. 2006-0209. https://norskoljeoggass.no/glo balassets/dokumenter/miljo/era-acute/report-1-era-acute-damage-and-restoration-2006.pdf

Stephansen C, Sørnes, TO, Skeie GM (2015). ERA Acute-development of seafloor compartment algorithms-biological modelling. Akvaplan-niva Report 5425.02. 126 pp. (Supplementary Material, Background Report 6 Seafloor compartment_ERA Acute 2015.pdf). https://norskolje oggass.no/globalassets/dokumenter/miljo/era-acute/report-6-era-acute-sea-floor-compartment2016.pdf

Stephansen C, Brude OW, Bjørgesæter A, Brönner U, Sørnes T, Kjeilen-Eilertsen G, Libre JM, Rogstad TW, Nygaard CF, Collin-Hanssen C, Johnsson H, Nordtug T, Reed M (2017a) ERA Acute-a multi-compartment environmental oil spill risk assessment model. Poster No. WE146, SETAC Europe Meeting, Brussels, May 2017. https://brussels.setac.org/wp-content/upl oads/2016/06/1702712_abstractbook.pdf

Stephansen C, Brude OW, Bjørgesæter A, Brönner U, Sørnes T, Kjeilen-Eilertsen G, Libre JM, Rogstad TW, Nygaard CF, Sørnes T, Skeie GM, Johnsson H, Rusten M, Nordtug T, Reed M, Collin-Hanssen C, Damsgaard-Jensen J (2017b)- ERA Acute-a multi-compartment quantitative risk assessment methodology for oil spills. Poster No. 2017-432. In: International oil spill conference, Long Beach, CA, USA 2017. http://ioscproceedings.org/doi/pdf/10.7901/21693358-2017.1.000432

Wenning R, Robinson H, Bock M, Rempel-Hester MA, Gardiner W (2018) Current practices and knowledge supporting oil spill risk assessment in the Arctic. Mar Environ Res 141(2018):289-304 
Open Access This chapter is licensed under the terms of the Creative Commons Attribution 4.0 International License (http://creativecommons.org/licenses/by/4.0/), which permits use, sharing, adaptation, distribution and reproduction in any medium or format, as long as you give appropriate credit to the original author(s) and the source, provide a link to the Creative Commons license and indicate if changes were made.

The images or other third party material in this chapter are included in the chapter's Creative Commons license, unless indicated otherwise in a credit line to the material. If material is not included in the chapter's Creative Commons license and your intended use is not permitted by statutory regulation or exceeds the permitted use, you will need to obtain permission directly from the copyright holder.

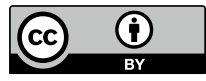

